\title{
Presence of purpura is related to active inflammation in association with IL-5 in eosinophilic granulomatosis with polyangiitis
}

\author{
Hiroshi Kataoka ${ }^{1}$ D $\cdot$ Tomoko Tomita $^{1} \cdot$ Makoto Kondo $^{1} \cdot$ Masaya Mukai $^{1}$
}

Received: 15 April 2020 / Accepted: 2 August 2020 / Published online: 7 August 2020

(c) The Author(s) 2020

\begin{abstract}
Eosinophilic granulomatosis with polyangiitis (EGPA) is a relatively rare necrotizing vasculitis that causes asthma, nasal involvement, peripheral nerve disturbance, renal disorder, and cutaneous lesions like purpura and is characterized by eosinophil infiltration into the damaged tissue. Purpura is the most common cutaneous lesion, but it remains unknown whether this skin lesion is associated with disease activity of EGPA and laboratory data including interleukin (IL)-5, a target cytokine of this disease. We conducted a search of our hospital electronic records for cases of EGPA from the last 10 years. Symptoms related to EGPA (fever, asthma, nasal and cutaneous manifestations, neuropathy), the Birmingham Vasculitis Activity Score (BVAS), and laboratory parameters, such as eosinophil count, urinalysis, antineutrophil cytoplasmic antibody (ANCA), CRP, IgE and IL-5, before and during treatment were compared among the eligible cases. A total of 28 EGPA patients (21 females and 7 males) were selected. Almost all developed peripheral neuropathy. Fever occurred in 25\%, nasal symptoms in $38.1 \%$ and purpura in $44 \%$. Glomerulonephritis developed in $7.7 \%$. One patient had cardiac involvement (3.6\%). The laboratory data showed a marked increase in peripheral eosinophil count, CRP, serum IgE and serum IL-5. ANCA was positive in $15.4 \%$. In the univariate analysis, presence of purpura was associated with increased CRP and IL-5, and high BVAS score. Multivariate analysis revealed a robust relationship between purpura and CRP. Our findings showed that presence of purpura was associated with increased CRP and IL-5, and high disease activity in EGPA.
\end{abstract}

Keywords Antineutrophil cytoplasmic antibody $\cdot$ Churg-Strauss syndrome $\cdot$ Eosinophils $\cdot$ Interleukin-5 $\cdot$ Purpura

\section{Introduction}

Eosinophilic granulomatosis with polyangiitis (EGPA) is a relatively rare necrotizing vasculitis resembling polyarteritis nodosa, which causes asthma, nasal involvement, peripheral nerve disturbance, heart and renal disorders, lymphadenopathy, cutaneous lesions like purpura and subcutaneous nodules with eosinophil infiltration into perivascular area and prominent eosinophilia $[1,2]$. The annual incidence of EGPA in Japan is 2.4 per million a year [3]. Prognosis is relatively poor, as $30-40 \%$ of patients experience relapse and mortality is $5-10 \%[4,5]$. In terms of classification of vasculitis, EGPA is a less common type of antineutrophil cytoplasmic antibody (ANCA)-related vasculitis, and $30-50 \%$ of EGPA cases are positive for ANCA [6]. EGPA

Hiroshi Kataoka

hiroshi.kataoka@doc.city.sapporo.jp

1 Department of Rheumatology and Clinical Immunology, Sapporo City General Hospital, Sapporo, Japan in the presence of heart and gastrointestinal lesions, and proteinuria, showed higher relapse rate [5]. Corticosteroid is essentially used for the treatment of this disease, and according to the severity of visceral damage, cyclophosphamide, azathioprine and biologic agents are concomitantly given to improve cardiac, gastrointestinal and neurological involvement $[7,8]$. To prevent irreversible damage in organs and nerves, treatment for EGPA should be commenced as soon as possible. However, there is a delay of 5-24 days from the onset because no reliable biomarker currently exists and the diagnosis of EGPA needs to be made on the basis of general consideration of clinical course and the laboratory data [8-10].

Skin involvement occurs in two-thirds of patients with EGPA, and when located at the area of the peripheral neuropathy, it is one of the clinical clues to diagnose EGPA [5, 11]. In this study, we sought to determine whether the presence of cutaneous involvement was associated with diagnosis of EGPA and decision of treatment by retrospectively 
analyzing manifestations, laboratory data and the factors that affected disease activity and treatment.

\section{Materials and methods}

\section{Patients}

The study design was a retrospective cross-sectional study in a single rheumatology center. Patients of EGPA were selected by searching electronic records using keywords of the disease names, such as eosinophilic granulomatosis with polyangiitis (EGPA), allergic granulomatous angiitis (AGA) and Churg-Strauss syndrome (CSS) for the recent 10 years (2009-2018). Enrolled patients were 18 years or older and their condition had been diagnosed as EGPA, AGA, or CSS and received induction and maintenance therapy for 6 months or more at our hospital. Patients who lacked detailed information at diagnosis or had been treated during the induction phase at other hospitals and whose subsequent maintenance therapy was taken over at our hospital were excluded. Diagnosis of EGPA was reconfirmed according to the American College of Rheumatology 1990 Criteria [12] on the basis of their history of the disease, results of physical examination, blood tests, imaging, nerve conduction test, and other information that were required for the diagnosis. Peripheral neuropathy was clinically diagnosed by neurologists at our hospital based on the nerve conduction test. Cutaneous involvement was diagnosed by dermatologists at our hospital primarily on the basis of clinical findings and the pathology of skin lesions with the patients' consent. Nasal lesions were diagnosed by otorhinolaryngologists at our hospital with reference to imaging studies and pathology. Systemic vasculitis activity was evaluated using the Birmingham Vasculitis Activity Score (BVAS) version 3 [13]. Symptoms at the onset of EGPA, changes in the laboratory parameters (eosinophil count, C-reactive protein [CRP], immunoglobulin [Ig] E, myeloperoxidase [MPO]-ANCA and interleukin [IL]-5) during treatment, initial and recent dose of prednisolone, and history of additional use of immunosuppressants were compared among the eligible cases. Quantification of IL-5 in the stored sera from the patients was performed using enzyme immunoassay at BML (Bio Medical Laboratories) Inc. The cut-off level that the company set was $4 \mathrm{pg} / \mathrm{ml}$.

\section{Bioethics}

This was a retrospective observational study, and the protocol was approved by the ethical committee of our hospital (H30-059-515); all participants provided written informed consent in accordance with the Declaration of Helsinki. Patients were notified of the protocol of this study at our hospital and could opt out of the patient list at any time.

\section{Statistical analysis}

Concerning statistical analysis, univariate analysis by unpaired $t$ test or the Mann-Whitney $U$ test was performed for comparison of each characteristic factor between patients with or without cutaneous lesions, after assessing the normality of the data using the D'Agostino and Pearson test as indicated in each table with the Prism 8 (version 8.4.1, GraphPad Software, LLC). The parameters with significant difference in the univariate analysis, were used in the multivariate linear regression analysis. In every analysis, a twotailed $p$ value less than 0.05 was considered as statistically significant.

\section{Results}

\section{Symptoms and laboratory data}

A total of 38 patients (28 females and 10 males) were selected as EGPA from our records (Fig. 1). Of 38 patients,
Fig. 1 Patient disposition. EGPA eosinophilic granulomatosis with polyangiitis, $A G A$ allergic granulomatous angiitis, CSS Churg-Strauss syndrome

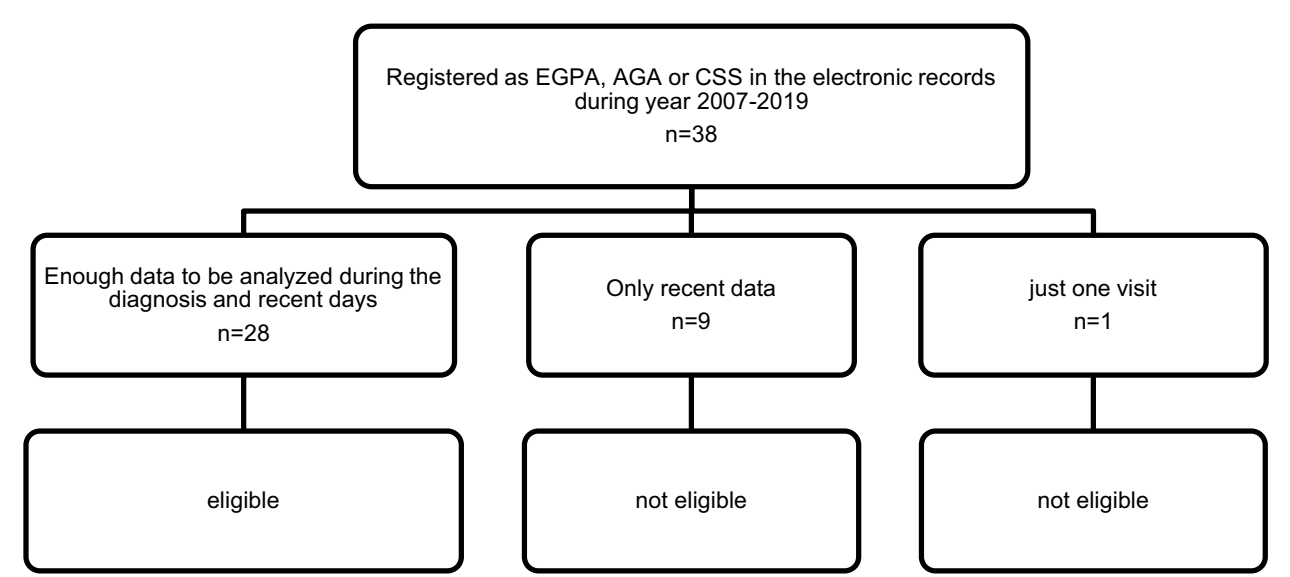


Table 1 Demographic data of EGPA patients

\begin{tabular}{ll}
\hline EGPA & $n=28$ \\
\hline Age (year) & $56 \pm 15$ \\
Disease duration (year) & $4.5 \pm 2.5$ \\
Fever (\%) & 25.0 \\
Weight loss over 2 kg/month (\%) & 30.0 \\
Nasal/sinus lesions (\%) & 38.1 \\
Cutaneous lesions (\%) & 44.0 \\
Peripheral neuropathy (\%) & 96.2 \\
Renal lesions (\%) & 7.7 \\
BVAS score (median, range) & $10(2-23)$ \\
\hline
\end{tabular}

BVAS score Birmingham Vasculitis Assessment Score ver. 3.0

28 ( 21 females and 7 males) had well-documented medical history about symptoms, laboratory data, images, pathology and medication that were eligible for further analysis (Table 1). Of 38 EGPA patients, nine patients had only recent records and data during quiescent state of the disease, and one patient visited our clinic just once. Thus, these ten patients were excluded from this study. The average age of the eligible 28 patients was 56 years and average disease duration was 4.5 years (Table 1 ). Of various initial symptoms, almost all patients $(96.2 \%)$ developed peripheral neuropathy. Fever occurred in $25 \%$, nasal symptom in $38.1 \%$ and cutaneous lesions in $44 \%$. Of 28,3 patients whose records lacked description about skin involvement were excluded from further analysis. Body weight loss of $2 \mathrm{~kg}$ or more per month occurred in $30 \%$. Urinalysis revealed that $7.7 \%$ (2 patients) showed hematuria and proteinuria. The renal biopsy revealed crescentic glomerulonephritis. One patient had cardiac involvement (3.6\%). In their laboratory data, there was a marked increase in peripheral eosinophil count $(10,639 \pm 9615 / \mu \mathrm{L}), \mathrm{CRP}(4.2 \pm 3.2 \mathrm{mg} / \mathrm{dl})$, serum $\operatorname{IgE}$ $(1514 \pm 1358 \mathrm{ng} / \mathrm{ml})$ and serum IL-5 $(94.1 \pm 101.1 \mathrm{pg} / \mathrm{ml})$. Including the two patients with nephritis as above, $15.4 \%$ (4 patients) of the patients showed positive ANCA (all MPOANCA, $179.3 \pm 98.4 \mathrm{IU} / \mathrm{ml})$. Initial CRP level correlated with serum levels of IL-5 and $\operatorname{IgE}\left(r^{2}=0.63\right.$ [ $\left.p=0.0006\right]$, 0.16 [ $p=0.038$ ], respectively) (Figs. 2, 3). The median BVAS score was 10 (range 2-23). Presence of cutaneous lesions was associated with elevated CRP, serum IL-5 and high BVAS score (Tables 2, 3). Multivariate linear regression analysis of CRP and IL-5 showed that only CRP was related to the presence of purpura ( $p=0.0223,95 \%$ confidence interval $0.022-0.21$, Table 3 ). In contrast, cutaneous lesions were irrespective of presence of nasal lesions, neurological disturbance and renal involvement or eosinophil count or serum IgE level (Table 2). Eosinophil count and CRP were not related to the BVAS score (data not shown). All cutaneous lesions were purpura, and skin biopsy was performed on 11 of them. The pathological findings were

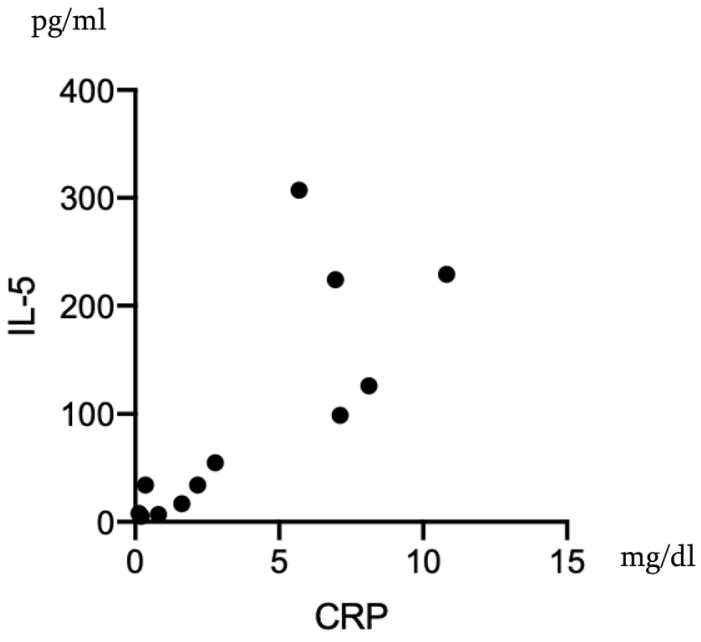

Fig. 2 Correlation of Serum IL-5 and CRP at the Onset of EGPA. Each plot represents each patient. Spearman $r^{2}=0.63(p=0.0006)$

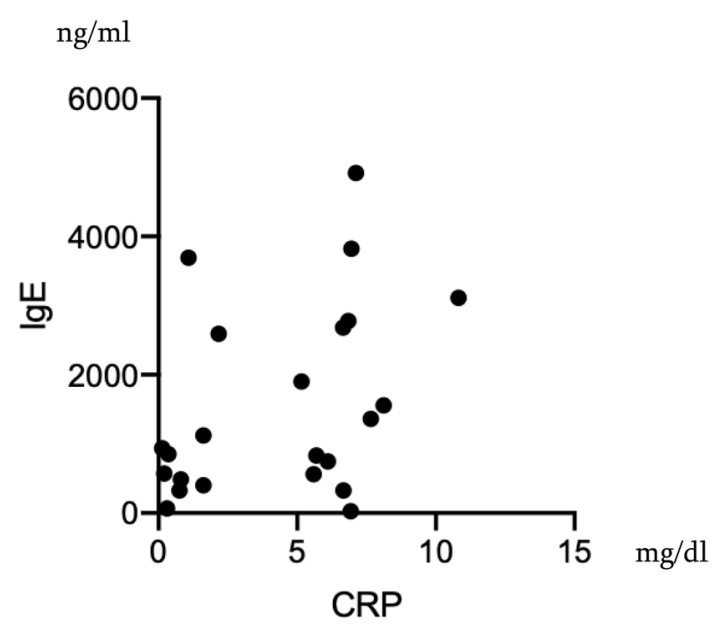

Fig. 3 Correlation of Serum IgE and CRP at the Onset of EGPA. Each plot represents each patient. Spearman $r^{2}=0.16(p=0.038)$

Table 2 Symptoms at the Onset of EGPA with or without Cutaneous Lesions

\begin{tabular}{llll}
\hline Cutaneous lesions $(n=25)$ & + & - & $p$ \\
\hline Patients & 11 & 14 & - \\
Age (year) & 58.7 & 54.5 & n.s \\
Fever (\%) & 30 & 16.7 & n.s \\
Nasal/sinus lesions (\%) & 55.6 & 27.3 & n.s \\
Cutaneous lesions (\%) & 100 & 0 & $<0.01^{*}$ \\
Peripheral neuropathy(\%) & 100 & 92.9 & n.s \\
Renal lesions (\%) & 10 & 7.1 & n.s \\
BVAS score & $14 \pm 4$ & $9 \pm 4$ & $<0.01^{* *}$ \\
\hline
\end{tabular}

Statistical analysis was done by *Fisher's exact test, **Mann-Whitney test 
Table 3 Parameters of EGPA at the onset with or without cutaneous lesions

\begin{tabular}{|c|c|c|c|c|c|}
\hline & \multicolumn{2}{|c|}{ Cutaneous lesions $(n=25)$} & \multirow{2}{*}{$\begin{array}{l}\text { Univariate } \\
p\end{array}$} & \multicolumn{2}{|c|}{ Multivariate } \\
\hline & + & - & & $p$ & $95 \% \mathrm{CI}$ \\
\hline Eosinophils $(/ \mu \mathrm{L})$ & $7648 \pm 4699$ & $13,635 \pm 12,135$ & 0.26 & - & - \\
\hline $\mathrm{CRP}(\mathrm{mg} / \mathrm{dl})$ & $6.2 \pm 2.7$ & $3.2 \pm 2.8$ & $0.022^{*}$ & 0.0223 & $0.022-0.21$ \\
\hline Positive ANCA (\%) & 20 & 8.3 & 0.99 & - & - \\
\hline $\operatorname{IgE}(\mathrm{IU} / \mathrm{ml})$ & $1728 \pm 1447$ & $1233 \pm 1153$ & 0.52 & - & - \\
\hline IL-5 (pg/ml) & $155.8 \pm 103.1$ & $50 \pm 78.8$ & $0.0303^{* *}$ & 0.93 & $-0.0034-0.0032$ \\
\hline
\end{tabular}

Statistical Univariate analysis was done by $* t$ test, **Mann-Whitney test
Table 4 Comparison of treatment for EGPA between patients with and without cutaneous lesions

\begin{tabular}{llll}
\hline Cutaneous lesions $(n=25)$ & + & - & $p$ \\
\hline mPSL pulse (\%) & 81.8 & 50 & $0.208^{\mathrm{a}}$ \\
Initial PSL dose (mg/dl) & $56.4 \pm 8.1$ & $51.5 \pm 12.1$ & $0.2739^{\mathrm{b}}$ \\
IVCY (\%) & 30 & 7.1 & $0.2721^{\mathrm{a}}$ \\
IVIG (\%) & 30 & 42.9 & $0.6785^{\mathrm{a}}$ \\
AZP (\%) & 10 & 21.4 & $0.6146^{\mathrm{a}}$ \\
ICS (\%) & 27.3 & 21.4 & $>0.99^{\mathrm{a}}$ \\
Pregabalin $(\%)$ & 50 & 28.6 & $0.4028^{\mathrm{a}}$ \\
Rituximab $(n)$ & 1 & 1 & - \\
\hline
\end{tabular}

mPSL methylprednisolone, PSL prednisolone, IVCY intravenous cyclophosphamide injection therapy, $I V I G$ intravenous immunoglobulin, $A Z P$ azathioprine, ICS inhalant corticosteroid

Statistical analysis was done by ${ }^{\mathrm{a}}$ Fisher's exact test, ${ }^{\mathrm{b}} t$ test

typical leukocytoclastic vasculitis in eight patients (73\%), and massive eosinophilic infiltration with other inflammatory cells in dermis was found in three patients. Concerning allergens, specific IgE was tested in seven patients. The allergens were Japanese white birch in one patient and candida in another, whereas no specific allergen was detected in five of them.

\section{Treatment and follow-up}

Methylprednisolone pulse therapy was introduced to $61.5 \%$ of the patients (Table 4). Initial prednisolone (PSL) was $53.6 \pm 10.4 \mathrm{mg} /$ day. Concomitant therapy included intravenous cyclophosphamide (IVCY) (16\%), intravenous immunoglobulin (IVIG) (34.6\%), rituximab (RTX) (7.1\%), azathioprine (AZP) (19.2\%), inhalant corticosteroid (ICS) $(26.9 \%)$ and pregabalin $(42.3 \%)$. In their treatment planning, cutaneous lesions did not affect the doctor's decision on mPSL pulse, initial PSL dose, IVCY, IVIG, RTX, AZP, ICS and pregabalin (Table 4). RTX was introduced to two patients with crescentic glomerulonephritis.

Total follow-up observation time was $3.7 \pm 2.3$ years. All enrolled patients visited our clinic every $4-12$ weeks. The average eosinophil count was $255 / \mu \mathrm{L}$ and mean CRP was 0.32 at the recent visit. PSL dose was $5.6 \pm 2.4 \mathrm{mg} /$ day at the final visit during the observation period. One case was omitted from calculating the observation time and PSL dose because she continued treatment at an adjacent hospital after our care and recent dose was unknown. One patient required increases in PSL dose (from 5 to $40 \mathrm{mg} /$ day) for the development of interstitial pneumonia (IP) in spite of remission for over a year. The patient recovered from IP and PSL was reduced to $5 \mathrm{mg} /$ day at the recent visit. No other patients experienced recurrence that required addition of PSL or immunosuppressant. There was no flare of glomerulonephritis in two patients and they did not require re-treatment with RTX. Mepolizumab was introduced to three patients at 1.2 years (median) from the onset because of recurrence of eosinophilia in all cases and worsening of asthma even after using constant ICS inhalation in one case. Follow-up IL-5 data were available in four patients including two patients using mepolizumab. IL-5 was tested in the most recently stored sera (those obtained before adding mepolizumab in cases treated with the biologic agent), and the results were under the cut-off level $(4 \mathrm{pg} / \mathrm{ml})$ in all patients.

\section{Discussion}

In this study, the presence of purpura was significantly associated with CRP, IL-5 and high BVAS score, suggesting that cutaneous lesions reflected high disease activity of EGPA (Tables 2, 3). Multivariate analysis showed that CRP was the most related marker to purpura (Table 3 ).

Cutaneous lesions as clinical manifestations in EGPA include purpura, which occurs in $25 \%$ of patients and is frequently found in their legs, nodules, urticaria, livedo and ulcers [14]. A French cohort of 383 patients also showed that, of the $39.7 \%$ of patients with skin lesions, purpura occurred in $22.5 \%$, urticaria in $9.9 \%$, subcutaneous nodules in $9.7 \%$, livedo reticularis in $3.9 \%$ and gangrenous necrotic lesions in $3.7 \%$ [4]. In our patients, purpura mainly developed in all patients with cutaneous involvement, and urticaria or livedo-like lesions were partly found in some cases. Leukocytoclastic vasculitis was the major findings in skin pathology, and 27\% showed massive eosinophil infiltration indicating eosinophilic inflammation in EGPA. 
IL-5 is a cytokine that belongs to the $\beta$ common chain family and mediates the differentiation and migration of eosinophil from blood to target tissue [15]. Th2 cells, mast cells, CD $34^{+}$progenitor cells, invariant natural killer $\mathrm{T}$ cells, group 2 innate lymphoid cells and eosinophils are major cellular sources of IL-5 [15, 16]. This cytokine stimulates eosinophil precursors to synthesize granule proteins, such as major basic protein (MBP), eosinophilderived neurotoxin (EDN), eosinophil peroxidase (EPX) and eosinophil cationic protein (ECP) [17]. IL-5 inhibits eosinophil adhesion to bone marrow sinus endothelium, resulting in mobilization of eosinophils to the peripheral tissues in conjunction with eotaxin. At the inflammation site, the recruited eosinophils are activated and degranulated to release the enzymes that cause tissue damage. Finally, dying eosinophils release self-DNA that forms extracellular DNA nets, which accelerates eosinophilic inflammation [17, 18]. As a result, systemic vasculitis in the skin, kidney, nerve, nasal cavity, and lung occurs along with the increased CRP in EGPA. Therefore, high CRP in patients with cutaneous lesions was thought to be a result of active eosinophilic inflammation of EGPA in relation to elevated IL-5.

Eosinophils in the peripheral blood produce massive IL-25 in EGPA [19]. IL-25 is also released from damaged epithelial cells, along with IL-33, as an alarmin [6]. These two cytokines stimulate type 2 innate lymphoid cells to induce IL-5 [6, 20]. Activated antigen-presenting cells, such as DC and IL-33, activate IL-33 receptor-expressing Th2 cells (i.e. pathogenic Th 2 cells) to produce IL-5 [21, 22]. In this way, eosinophils promote and enhance Th2 response in the inflammatory site.

This study has certain limitations. First, the number of the eligible patients was small and second, this was a retrospective study conducted in a single center. Treatment strategy of each patient was dependent on a patient's choice or a doctor's decision. The results of this study do not offer the best choice, such as PSL monotherapy or the addition of IVCY or mepolizumab, for each case based on the presence or absence of purpura, although the presence of purpura indicated the disease activity of EGPA. A multicenter prospective cohort study may reveal the requirement of immunosuppressants or biologics for EGPA with purpura as the diagnosis. Moreover, as mepolizumab inhibits IL-5 directly, the efficacy of this biologic agent would elucidate how IL-5 is involved in the development of cutaneous lesions.

We have concluded that a cutaneous lesion like purpura is an important index indicating robust inflammation in connection with increased IL-5 and eventually high disease activity of EGPA. Further study with more patients enrolled may provide better choices of combination of PSL, IVCY, IVIG, and anti-IL-5 therapy on the basis of clinical and laboratory findings.
Acknowledgements The edit was performed by professional editors at Editage, a division of Cactus Communications.

Author contributions HK designed the study, collected and analyzed data, and wrote the manuscript. TT, MK and MM contributed to data collection, interpretation of data and critical review of the original and revised manuscript. All authors read and approved the final manuscript and agreed to be accountable for all aspects of the work in ensuring that questions related to the accuracy or integrity of any part of the work are appropriately investigated and resolved.

Funding The authors received no financial support for the research, authorship, and publication of this article.

Data availability The datasets concerning the current study made on Microsoft Word for Mac version 16.37 and Microsoft Excel for Mac version 16.37 are available from the corresponding author on reasonable request.

\section{Compliance with ethical standards}

Conflict of interest All the authors have no conflict of interest to declare.

Ethics approval The protocol was approved by the ethical committee of Sapporo City General hospital (H30-059-515).

Consent to participate All participants provided written informed consent in accordance with the Declaration of Helsinki. Patients were notified of the protocol of this study in our hospital and could opt out of the patient list at any time.

Consent to publish All participants provided written informed consent regarding publishing their data.

Open Access This article is licensed under a Creative Commons Attribution 4.0 International License, which permits use, sharing, adaptation, distribution and reproduction in any medium or format, as long as you give appropriate credit to the original author(s) and the source, provide a link to the Creative Commons licence, and indicate if changes were made. The images or other third party material in this article are included in the article's Creative Commons licence, unless indicated otherwise in a credit line to the material. If material is not included in the article's Creative Commons licence and your intended use is not permitted by statutory regulation or exceeds the permitted use, you will need to obtain permission directly from the copyright holder. To view a copy of this licence, visit http://creativecommons.org/licenses/by/4.0/.

\section{References}

1. Churg J, Strauss L (1951) Allergic granulomatosis, allergic angiitis, and periarteritis nodosa. Am J Pathol 27(2):277-301

2. Strauss L, Churg J, Zak FG (1951) Cutaneous lesions of allergic granulomatosis; a histopathologic study. J Invest Dermatol 17(6):349-359. https://doi.org/10.1038/jid.1951.103

3. Fujimoto S, Watts RA, Kobayashi S, Suzuki K, Jayne DR, Scott DG, Hashimoto H, Nunoi H (2011) Comparison of the epidemiology of anti-neutrophil cytoplasmic antibody-associated vasculitis between Japan and the UK. Rheumatology (Oxford) 50(10):19161920. https://doi.org/10.1093/rheumatology/ker205 
4. Comarmond C, Pagnoux C, Khellaf M, Cordier JF, Hamidou M, Viallard JF, Maurier F, Jouneau S, Bienvenu B, Puechal X, Aumaitre O, Le Guenno G, Le Quellec A, Cevallos R, Fain O, Godeau B, Seror R, Dunogue B, Mahr A, Guilpain P, Cohen P, Aouba A, Mouthon L, Guillevin L, French Vasculitis Study G (2013) Eosinophilic granulomatosis with polyangiitis (ChurgStrauss): clinical characteristics and long-term followup of the 383 patients enrolled in the French Vasculitis Study Group cohort. Arthritis Rheum 65(1):270-281. https://doi.org/10.1002/art.37721

5. Tsurikisawa N, Oshikata C, Kinoshita A, Tsuburai T, Saito H (2017) Longterm prognosis of 121 patients with eosinophilic granulomatosis with polyangiitis in Japan. J Rheumatol 44(8):1206-1215. https://doi.org/10.3899/jrheum.161436

6. Furuta S, Iwamoto T, Nakajima H (2019) Update on eosinophilic granulomatosis with polyangiitis. Allergol Int 68(4):430-436. https://doi.org/10.1016/j.alit.2019.06.004

7. Taniguchi M, Tsurikisawa N, Higashi N, Saito H, Mita H, Mori A, Sakakibara H, Akiyama K (2007) Treatment for Churg-Strauss syndrome: induction of remission and efficacy of intravenous immunoglobulin therapy. Allergol Int 56(2):97-103. https://doi. org/10.2332/allergolint.R-07-142

8. Groh M, Pagnoux C, Baldini C, Bel E, Bottero P, Cottin V, Dalhoff K, Dunogue B, Gross W, Holle J, Humbert M, Jayne D, Jennette JC, Lazor R, Mahr A, Merkel PA, Mouthon L, Sinico RA, Specks U, Vaglio A, Wechsler ME, Cordier JF, Guillevin L (2015) Eosinophilic granulomatosis with polyangiitis (Churg-Strauss) (EGPA) Consensus Task Force recommendations for evaluation and management. Eur J Intern Med 26(7):545-553. https://doi. org/10.1016/j.ejim.2015.04.022

9. Grayson PC, Monach PA, Pagnoux C, Cuthbertson D, Carette S, Hoffman GS, Khalidi NA, Koening CL, Langford CA, Maksimowicz-McKinnon K, Seo P, Specks U, Ytterberg SR, Merkel PA, Vasculitis Clinical Research C (2015) Value of commonly measured laboratory tests as biomarkers of disease activity and predictors of relapse in eosinophilic granulomatosis with polyangiitis. Rheumatology (Oxford) 54(8):1351-1359. https://doi. org/10.1093/rheumatology/keu427

10. Oiwa H, Mokuda S, Matsubara T, Funaki M, Takeda I, Yamawaki T, Kumagai K, Sugiyama E (2017) Neurological complications in eosinophilic granulomatosis with polyangiitis (EGPA): the roles of history and physical examinations in the diagnosis of EGPA. Intern Med 56(22):3003-3008. https://doi.org/10.2169/internalme dicine.8457-16

11. Kawakami T, Soma Y, Kawasaki K, Kawase A, Mizoguchi M (2005) Initial cutaneous manifestations consistent with mononeuropathy multiplex in Churg-Strauss syndrome. Arch Dermatol 141(7):873-878. https://doi.org/10.1001/archderm.141.7.873

12. Masi AT, Hunder GG, Lie JT, Michel BA, Bloch DA, Arend WP, Calabrese LH, Edworthy SM, Fauci AS, Leavitt RY et al (1990) The American College of Rheumatology 1990 criteria for the classification of Churg-Strauss syndrome (allergic granulomatosis and angiitis). Arthritis Rheum 33(8):1094-1100

13. Mukhtyar C, Lee R, Brown D, Carruthers D, Dasgupta B, Dubey S, Flossmann O, Hall C, Hollywood J, Jayne D, Jones R, Lanyon P, Muir A, Scott D, Young L, Luqmani RA (2009) Modification and validation of the Birmingham Vasculitis Activity Score (version 3). Ann Rheum Dis 68(12):1827-1832. https://doi. org/10.1136/ard.2008.101279

14. Vaglio A, Buzio C, Zwerina J (2013) Eosinophilic granulomatosis with polyangiitis (Churg-Strauss): state of the art. Allergy 68(3):261-273. https://doi.org/10.1111/all.12088

15. Varricchi G, Bagnasco D, Borriello F, Heffler E, Canonica GW (2016) Interleukin-5 pathway inhibition in the treatment of eosinophilic respiratory disorders: evidence and unmet needs. Curr Opin Allergy Clin Immunol 16(2):186-200. https://doi.org/10.1097/ ACI.0000000000000251

16. Nussbaum JC, Van Dyken SJ, von Moltke J, Cheng LE, Mohapatra A, Molofsky AB, Thornton EE, Krummel MF, Chawla A, Liang HE, Locksley RM (2013) Type 2 innate lymphoid cells control eosinophil homeostasis. Nature 502(7470):245-248. https://doi. org/10.1038/nature12526

17. Gleich GJ (2000) Mechanisms of eosinophil-associated inflammation. J Allergy Clin Immunol 105(4):651-663. https://doi. org/10.1067/mai.2000.105712

18. Ueki S, Melo RC, Ghiran I, Spencer LA, Dvorak AM, Weller PF (2013) Eosinophil extracellular DNA trap cell death mediates lytic release of free secretion-competent eosinophil granules in humans. Blood 121(11):2074-2083. https://doi.org/10.1182/blood -2012-05-432088

19. Terrier B, Bieche I, Maisonobe T, Laurendeau I, Rosenzwajg M, Kahn JE, Diemert MC, Musset L, Vidaud M, Sene D, Costedoat-Chalumeau N, Le Thi-Huong D, Amoura Z, Klatzmann D, Cacoub P, Saadoun D (2010) Interleukin-25: a cytokine linking eosinophils and adaptive immunity in Churg-Strauss syndrome. Blood 116(22):4523-4531. https://doi.org/10.1182/blood-201002-267542

20. Moro K, Yamada T, Tanabe M, Takeuchi T, Ikawa T, Kawamoto H, Furusawa J, Ohtani M, Fujii H, Koyasu S (2010) Innate production of $\mathrm{T}(\mathrm{H}) 2$ cytokines by adipose tissue-associated c-Kit(+) Sca-1(+) lymphoid cells. Nature 463(7280):540-544. https://doi. org/10.1038/nature08636

21. Endo Y, Iwamura C, Kuwahara M, Suzuki A, Sugaya K, Tumes DJ, Tokoyoda K, Hosokawa H, Yamashita M, Nakayama T (2011) Eomesodermin controls interleukin-5 production in memory $\mathrm{T}$ helper 2 cells through inhibition of activity of the transcription factor GATA3. Immunity 35(5):733-745. https://doi. org/10.1016/j.immuni.2011.08.017

22. Endo Y, Hirahara K, Iinuma T, Shinoda K, Tumes DJ, Asou HK, Matsugae N, Obata-Ninomiya K, Yamamoto H, Motohashi S, Oboki K, Nakae S, Saito H, Okamoto Y, Nakayama T (2015) The interleukin-33-p38 kinase axis confers memory T helper 2 cell pathogenicity in the airway. Immunity 42(2):294-308. https://doi. org/10.1016/j.immuni.2015.01.016

Publisher's Note Springer Nature remains neutral with regard to jurisdictional claims in published maps and institutional affiliations. 